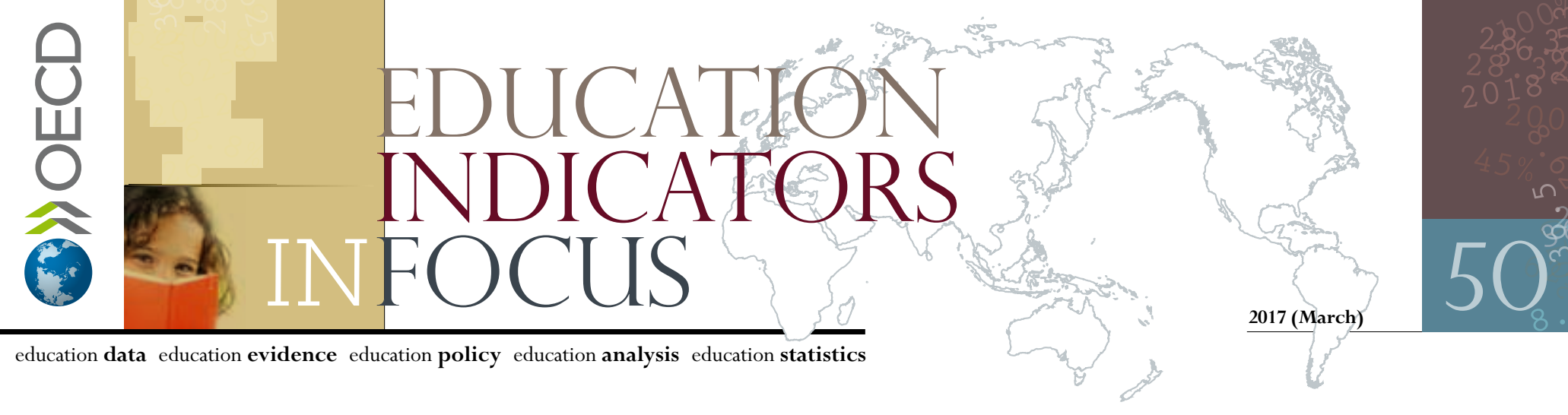

\title{
Educational attainment and investment in education in Ibero-American countries
}

- Adults in all the Ibero-American countries covered by Education at a Glance are less likely to have an upper secondary education than the average across OECD countries, although the gap is narrower among the younger generation.

- The share of 25-34 year-olds with tertiary education across OECD countries is much higher than the share of 55-64 year-olds. This is also the case for Ibero-American countries, but only in Portugal and Spain is the increase above the OECD average, while other Ibero-American countries are lagging behind.

- Ibero-American governments face increasing demand for education. Chile, Colombia, Costa Rica and Portugal devote a larger share of private expenditure on tertiary educational institutions than the average across OECD countries, as a percentage of GDP.

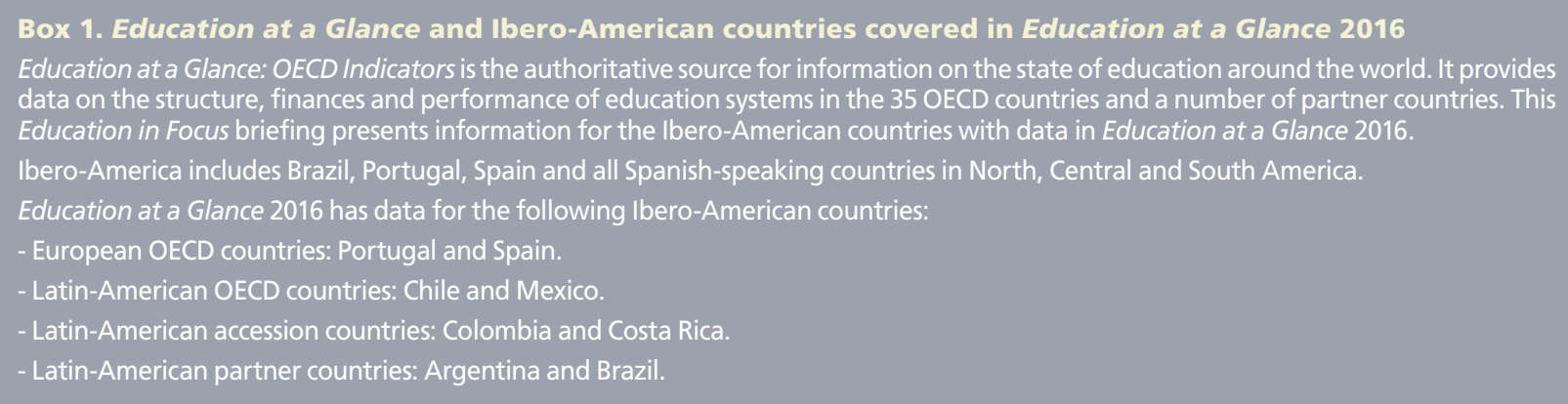

Educational attainment levels in Ibero-American countries are quite different from the OECD average

Across OECD countries, $16 \%$ of 25-34 year-olds have not completed an upper secondary education, $42 \%$ have an upper secondary education as their highest level of education and $42 \%$ have a tertiary degree. In all Ibero-American countries, the structure of the educational attainment is quite different - in particular, they all have a much larger share of young adults without an upper secondary qualification, and a much smaller share with a tertiary degree (Figure 1).

Figure 1. Percentage of 25-34 year-olds by educational attainment (2015)

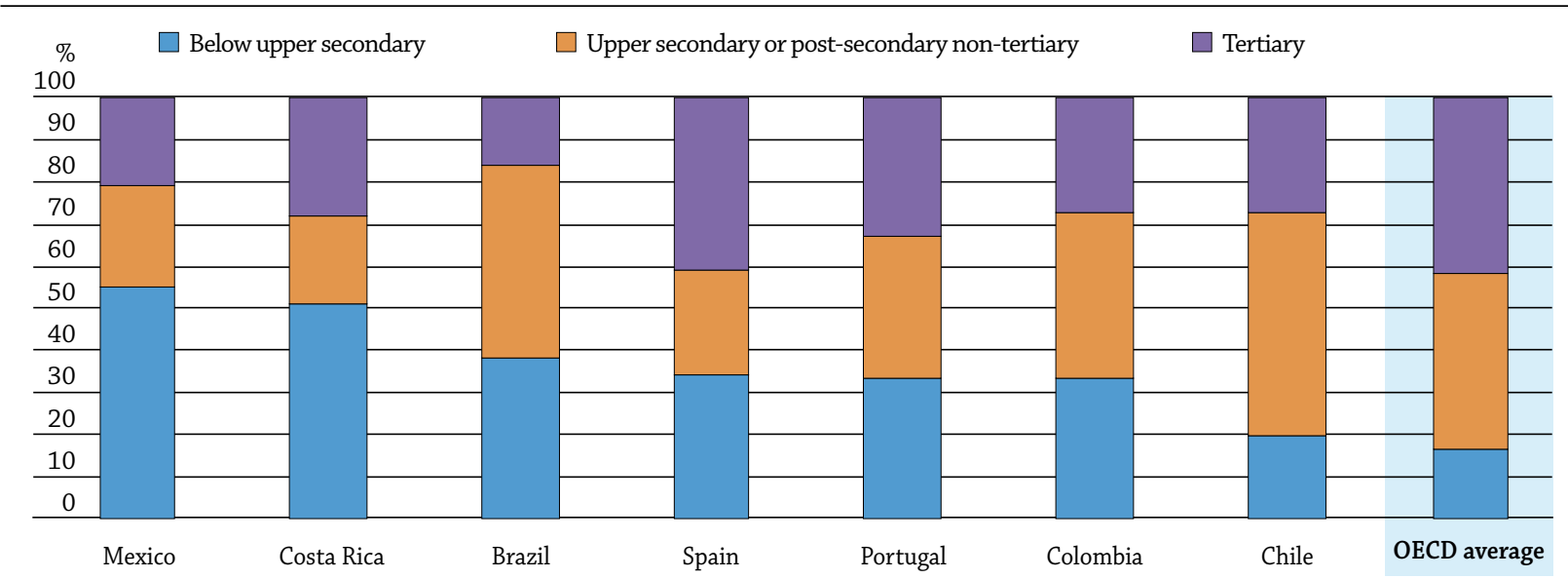

Note: Year of reference is 2014 for Brazil and 2013 for Chile.

Countries are ranked in descending order of the share of young adults with below upper secondary education.

Source: OECD, Education at a Glance (database), http://stats.oecd.org. 


\section{A large share of young adults without upper secondary education}

Completion of upper secondary education is the minimum threshold for successful entry into the labour market, and for continued employability. In OECD countries, adults who have not completed this level of education have the highest unemployment and inactivity rates, and lower and more rapidly declining wages over their working lives, in particular during the years before retirement. A large population of low-qualified workers may thus lead to significant public expenditure on social security and result in deepening inequalities that are both difficult and costly to address once people have left education.

Over recent decades, the share of adults who have not completed upper secondary education fell in the majority of OECD and partner countries, to just 23\% among 25-64 year-olds in 2015 on average across OECD countries. Based on Education at a Glance 2016 data, Ibero-American countries are lagging behind this trend, with high percentages of adults without upper secondary education: about 60\% in Costa Rica and Mexico; about 50\% in Brazil, Colombia and Portugal; and about 40\% in Chile and Spain. Moreover, as the Programme for International Student Assessment (PISA) reminds us, better access to secondary education has not always been matched by increases in learning outcomes.

Among the younger generation, a higher share of young adults is completing upper secondary education in Ibero-American countries. The differences across generations are more pronounced in Ibero-American countries than in OECD countries as a whole, partly because the share of adults without upper secondary education is much higher among older generations. Portugal, Chile and Colombia are the countries showing the strongest progress in increasing completion of upper secondary education across generations. It is noteworthy that the share of young adults without upper secondary education in Chile is similar to the OECD average. At the other end of the spectrum, progress has been slower in Costa Rica and Mexico, where more than half of young adults still have not completed their upper secondary education (Figure 2)

Figure 2. Percentage of adults with less than upper secondary education, by age group (2015)

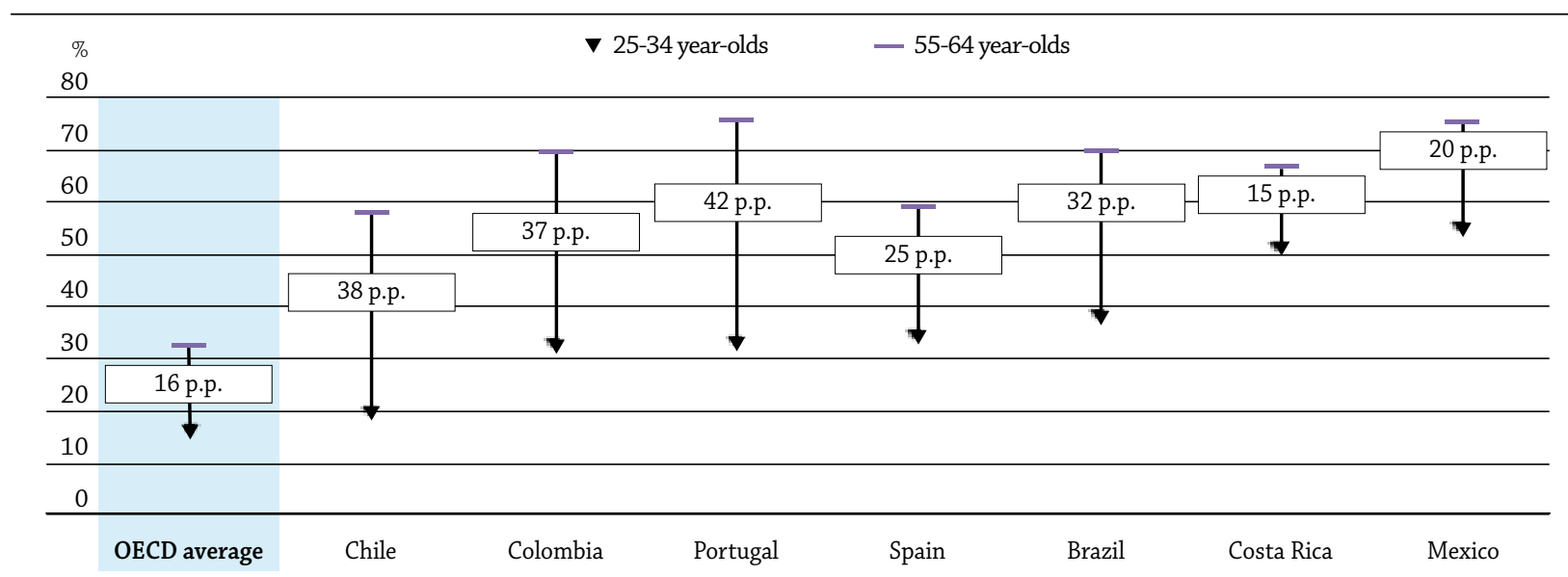

Note: Year of reference is 2014 for Brazil and 2013 for Chile. Figures in the chart represent the percentage-point difference (p.p.) between the percentage of older and younger adults with less than upper secondary education.

Countries are ranked in ascending order of the percentage of 25-34 year-olds with less than upper secondary education.

Source: OECD, Education at a Glance (database), http://stats.oecd.org.

\section{The picture is improving as the demand for education grows, especially at the tertiary level}

Tertiary education has also seen an increasing uptake, but most Ibero-American countries still lag far behind the OECD average. The share of young adults with tertiary education has steadily increased in OECD countries. Among Ibero-American countries, the increase has been largest in Portugal and Spain, where the percentage of tertiary-educated 25-34 year-olds is now about 20 percentage points higher than that of 55-64 year-olds. In the other Ibero-American countries covered, the improvement has been lower than the OECD average of 16 percentage points. In particular, in Brazil, Costa Rica and Mexico, tertiary-education rates have increased by less than ten percentage points between the two generations. Good measures for assessing the quality of tertiary education and the learning outcomes of students and graduates still have to be developed, but data from the Survey of Adult Skills, a product of the Programme for International Assessment of Adult Competencies (PIAAC), suggest that tertiary attainment not always guarantees equivalent skills levels and that huge disparities exist in the level of skills of graduates, both between and within countries.

Spain is the only Ibero-American country with a similar share of tertiary-educated young adults to the OECD average (41\% and $42 \%$, respectively). In Portugal, one in three young adults is tertiory educated, and in the remaining countries the share is below $30 \%$, the lowest being in Brazil (16\%) and Mexico (21\%).

The growth in tertiary attainment is even more pronounced among women, as women in the older generation were less likely to gain a tertiary degree than men. As across OECD countries, in Ibero-American countries the share of young tertiary-educated women 
is larger than the share of young men. But despite overtaking their male peers, in Ibero-American countries the distance from the OECD average is still larger for young women than for young men, except in Portugal. This is particularly true for young women in Chile and Mexico, where the gap between them and their OECD peers is at least twice as large as it is for young men.

A number of social and economic outcomes in an individual's life are associated with education. Educational attainment is positively associated with social outcomes including health status, volunteering, interpersonal trust and political efficacy. Labour markets reward adults with tertiary degrees with higher earnings relative to those with upper secondary education as their highest degree. On average in OECD countries, tertiary-educated adults earn about 55\% more for full-time work than adults with an upper secondary education. Four Ibero-American countries report the highest advantages for tertiary-educated adults among all OECD and partner countries: Brazil (141\%), Chile (139\%), Colombia (133\%) and Mexico (105\%).

\section{Households' contribution to compulsory education is high}

It is well known that substantial levels of investment in education are needed to support students' educational attainment. Public and private expenditure in education in Ibero-American countries remains relatively low in absolute terms, but corresponds to a comparatively high share of gross domestic product (GDP).

As in OECD countries generally, most spending in Ibero-American countries on compulsory education is public but private expenditure makes up a larger proportion of the total than the OECD average. Colombia has the highest rate of private spending, at $1.0 \%$ of GDP, and Spain has the lowest, at $0.4 \%$. Private expenditure in Chile is two times higher than the OECD average $(0.7 \%$ and $0.3 \%$, respectively), but total expenditure is still below the average (3.1\% and $3.6 \%$, respectively). These figures highlight the greater importance of funds from private sources in compulsory education within Ibero-American countries, and indeed in supporting educational attainment, than in other OECD countries.

Increasing demand for higher education has been funded from a mixture of public and private sources Rising participation in tertiary education in Ibero-American countries has also been accompanied by an expansion of private spending on education. As in many other OECD countries, many lbero-American governments are finding it difficult to provide the necessary resources needed to meet the increased demand for education through public funds alone.

In general, in Ibero-American countries the share of private expenditure on tertiary educational institutions as a percentage of GDP is larger than the average of $0.5 \%$ across OECD countries. In Chile it is $1.4 \%$, in Colombia $1.1 \%$, in Costa Rica $1.0 \%$ and in Portugal $0.5 \%$.

The greater need for private funding to acquire a university education might limit access to tertiary education. The Ibero-American countries with a larger share of private expenditure relative to GDP than the OECD average tend to have a lower attainment levels in tertiary education, with the exception of Mexico. Chile, Colombia and Costa Rica, which devote a relatively large share of private expenditure on tertiary education, show the lowest tertiary educational attainment in young adults (around 14 percentage points lower than the OECD average). In contrast, lower levels of private funding, as in Portugal and Spain, are associated with higher educational attainment in tertiary education (Figure 3).

Figure 3. Private expenditure on educational institutions as a percentage of GDP (2013) and the share of young adults with tertiary education (2015)

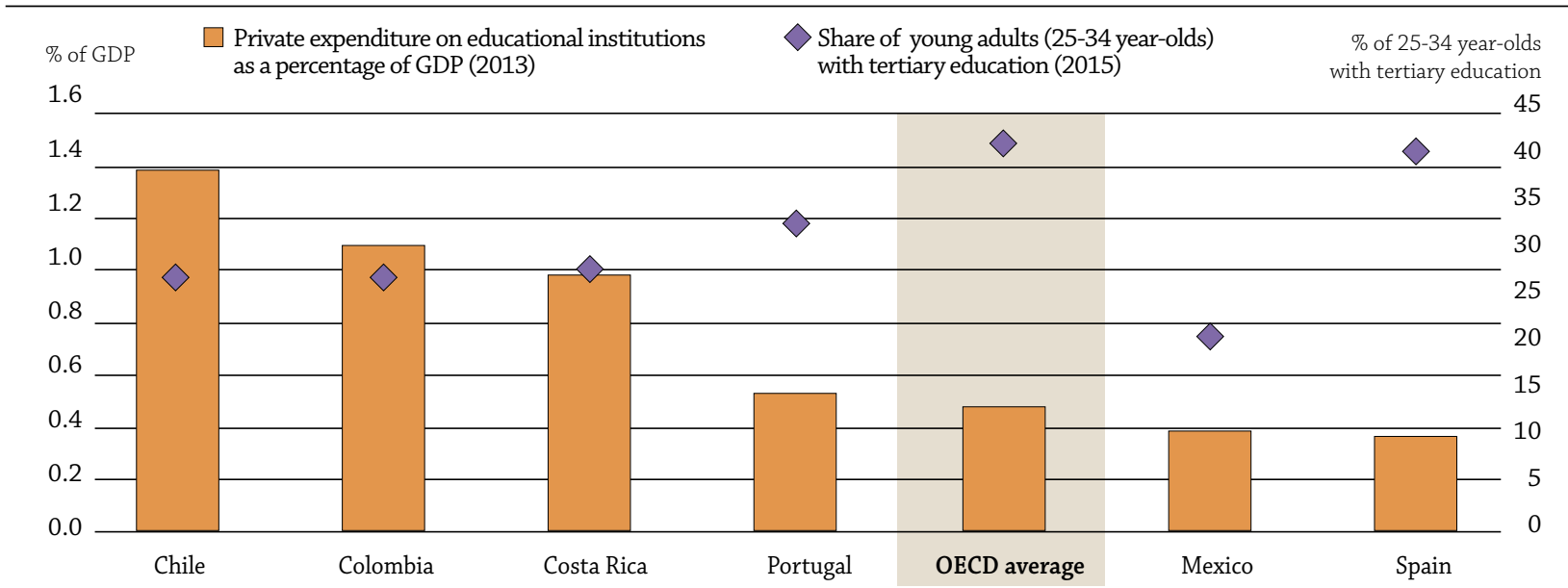

Note: Chile data refer to 2014 and do not include international sources. Private investment includes expenditure by students and households and expenditure by other private entities.

Countries are ranked in descending order of the private expenditure as a percentage of GDP.

Source: OECD, Education at a Glance (database), http://stats.oecd.org. 
In Latin-American countries higher expenditure on education can positively impact PISA science scores

The Programme for International Student Assessment (PISA) assesses the extent to which 15-year-old students, near the end of their compulsory education, have acquired key knowledge and skills that are essential for full participation in modern societies. The most recent assessment, which was implemented in 73 countries and economies during 2015, shows that higher spending on education is positively associated with science performance up to an average value of spending per student of USD 50000 (Figure 4). Average spending per students from 6 to 15 years old demonstrates the cumulative effect that spending may have on education outcomes throughout a student's time spent in school. Spending per student in most Ibero-American countries is below the threshold of USD 50 000, indicating that increasing the level of spending could improve their capacity to provide quality education for all students.

Figure 4. Spending per student from the age of 6 to 15 (2013) and science performance in PISA (2015)

$\square$ Countries/economies whose cumulative expenditure per student in 2013 was less than USD 50 000
Countries/economies whose cumulative expenditure per student in 2013 was USD 50 000 or more

Note: Only Ibero-American countries in EAG 2016 are labelled in the figure but all countries and economies with available data in the PISA 2015 database have been used for the computation of the regression lines. A significant relationship ( $<<0.10)$ is shown by the thin line. A nonsignificant relationship ( $\mathrm{p}>0.10$ ) is shown by the thick line.

Source: OECD, PISA 2015 Results, Volume II database, http://dx.doi.org/10.1787/888933436215, Figure II.6.2.

The bottom line: Despite the geographical distances between them, Ibero-American countries share some similarities in their educational attainment rates and private expenditure on educational institutions as a percentage of GDP. Across all Ibero-American countries covered in Education at a Glance, there is a higher than average share of adults without an upper secondary education. Even though the gap is declining, the share of less well-educated adults still remains higher than the OECD average among the younger generation. In parallel, private expenditure on educational institutions as a percentage of GDP is generally higher in Ibero-American countries than on average across OECD countries. These features contribute to explaining socio-economic inequalities in Ibero-American countries, with those who can afford to pay for their (or their children's) education obtaining access to better jobs and higher salaries, thus enabling them to move up the social ladder.

\section{For more information}

- OECD (2016a), Education at a Glance 2016: OECD Indicators, OECD Publishing, Paris, http://dx.doi.org/10.1787/eag-2016-en.

- OECD (2016b), PISA 2015 Results (Volume II): Policies and Practices for Successful Schools, OECD Publishing, Paris, http://dx.doi. org/10.1787/9789264267510-en.

- OECD (2016c), Skills Matter: Further Results from the Survey of Adult Skills, OECD Skills Studies, OECD Publishing, Paris, http://dx.doi. org/10.1787/9789264258051-en.

Data and more breakdowns available at http://stats.oecd.org/, Education at a Glance (database).

\section{Contact}

Gara Rojas González (Gara.RojasGonzalez@oecd.org) and Daniel Sánchez Serra (Daniel.SanchezSerra@oecd.org)

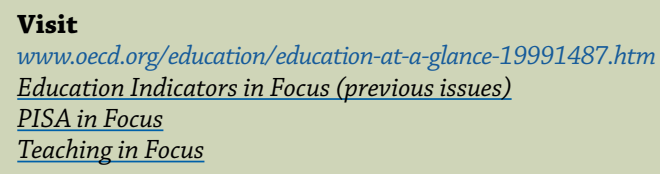

Visit

www.oecd.org/education/education-at-a-glance-19991487.htm

Education Indicators in Focus (previous issues)

PISA in Focus

Teaching in Focus

Photo credit: @ Ghislain \& Marie David de Lossy/Cultura/Getty Images

This work is published under the responsibility of the Secretary-General of the OECD. The opinions expressed and arguments employed herein do not necessarily reflect the official views of OECD member countries.

This document and any map included herein are without prejudice to the status of or sovereignty over any territory, to the delimitation of international frontiers and boundaries and to the name of any territory, city or area.

The statistical data for Israel are supplied by and are under the responsibility of the relevant Israeli authorities. The use of such data by the OECD is without prejudice to the status of the Golan Heights, East Jerusalem and Israeli settlements in the West Bank under the terms of international law. 